\title{
Geographic Access to Breast Imaging for US Women
}

\section{Citation}

Onega, Tracy, Rebecca Hubbard, Deirdre Hill, Christoph I. Lee, Jennifer S. Haas, Heather A. Carlos, Jennifer Alford-Teaster, et al. 2014. Geographic Access to Breast Imaging for US Women. Journal of the American College of Radiology 11, no. 9: 874-882. doi:10.1016/j.jacr.2014.03.022.

\section{Published Version}

doi:10.1016/j.jacr.2014.03.022

\section{Permanent link}

http://nrs.harvard.edu/urn-3:HUL.InstRepos:37134140

\section{Terms of Use}

This article was downloaded from Harvard University's DASH repository, and is made available under the terms and conditions applicable to Open Access Policy Articles, as set forth at http:// nrs.harvard.edu/urn-3:HUL.InstRepos:dash.current.terms-of-use\#OAP

\section{Share Your Story}

The Harvard community has made this article openly available.

Please share how this access benefits you. Submit a story.

Accessibility 
Published in final edited form as:

J Am Coll Radiol. 2014 September ; 11(9): 874-882. doi:10.1016/j.jacr.2014.03.022.

\section{Geographic Access to Breast Imaging for U.S. Women}

Tracy Onega, MS, $\mathrm{PhD}^{1,2,3}$, Rebecca Hubbard, $\mathrm{PhD}^{4}$, Deirdre Hill, $\mathrm{PhD}^{5}$, Christoph Lee, MD, MSHS $^{6}$, Jennifer S. Haas, MD, MS ${ }^{7}$, Heather A. Carlos, MS $^{2}$, Jennifer Alford-Teaster, MA, MPH $^{1,2}$, Andy Bogart, MS ${ }^{4}$, Wendy B. DeMartini, MD ${ }^{12}$, Karla Kerlikowske, MD ${ }^{9}$, Beth A. Virnig, $\mathrm{PhD}^{8}$, Diana S.M. Buist, $\mathrm{PhD}^{4}$, Louise Henderson, $\mathrm{PhD}^{11}$, and Anna N. A. Ttosteson, $\mathrm{ScD}^{1,2,3}$

${ }^{1}$ Department of Community \& Family Medicine, Geisel School of Medicine at Dartmouth, Lebanon, $\mathrm{NH}$

${ }^{2}$ Norris Cotton Cancer Center, Geisel School of Medicine at Dartmouth, Lebanon, NH

${ }^{3}$ The Dartmouth Institute for Health Policy and Clinical Practice, Geisel School of Medicine at Dartmouth, Lebanon, $\mathrm{NH}$

${ }^{4}$ Group Health Research Institute, Seattle, WA

${ }^{5}$ University of New Mexico, Albuquerque, NM

${ }^{6}$ Department of Radiology, University of Washington School of Medicine, Seattle, WA; Department of Health Services, University of Washington School of Public Health, Seattle, WA

${ }^{7}$ Division of General Internal Medicine, Brigham and Women's Hospital, Boston, MA

${ }^{8}$ School of Public Health, University of Minnesota, Minneapolis, MN

${ }^{9}$ Departments of Medicine and Epidemiology and Biostatistics, University of California, San Francisco, CA

${ }^{10}$ General Internal Medicine Section, Department of Veterans Affairs, University of California, San Francisco, CA

${ }^{11}$ Department of Radiology, The University of North Carolina, Chapel Hill, NC

${ }^{12}$ Department of Radiology, University of Wisconsin School of Medicine and Public Health, Madison, WI 53792-3252

\section{Abstract}

\footnotetext{
(C) 2014 American College of Radiology. Published by Elsevier Inc. All rights reserved.

Corresponding Author: Tracy Onega, PhD, HB 7927 Rubin 8, Geisel School of Medicine at Dartmouth, Lebanon, NH 03756, Tracy.L.Onega@dartmouth.edu.

Disclosures: The authors have no financial disclosures related to the funding of this specific project by the NIH. However, Wendy B. DeMartini, MD receives grant support from both GE Health Care and Phillips Medical Systems.

Travel time to mammography and ultrasound for most U.S. women (85\%) is $\leq 20$ minutes. Native American and rural women have a disproportionately high travel burden to breast imaging modalities.

Publisher's Disclaimer: This is a PDF file of an unedited manuscript that has been accepted for publication. As a service to our customers we are providing this early version of the manuscript. The manuscript will undergo copyediting, typesetting, and review of the resulting proof before it is published in its final citable form. Please note that during the production process errors may be discovered which could affect the content, and all legal disclaimers that apply to the journal pertain.
} 
Background-The breast imaging modalities of mammography, ultrasound, and magnetic resonance imaging (MRI) are widely used for screening, diagnosis, treatment, and surveillance of breast cancer. Geographic access to breast imaging modalities is not known at a national level overall or for population subgroups.

Methods-A retrospective study of 2004-2008 Medicare claims data to identify ZIP codes in which breast imaging occurred, and data were mapped. We estimated travel times to each modality for 215,798 census block groups in the contiguous U.S. Using Census 2010 data, we characterized travel times by socio-demographic factors for $92,788,909$ women aged $\geq 30$ years, overall, and by subgroups of age, race/ethnicity, rurality, education, and median income.

Results-Overall, $85 \%$ of women had travel times of $\_20$ minutes to nearest mammography or ultrasound, and $70 \%$ had travel times of $\_20$ minutes for MRI with little variation by age. Native American women had median travel times 2-3-fold longer to all three modalities, compared to women of other racial/ethnic groups. For rural women, median travel times to breast imaging were 4-8-fold longer than for urban women. Black and Asian women had shortest median travel times to all three modalities.

Conclusion-Travel times to mammography and ultrasound breast imaging are short for most women, but to breast MRI travel times are notably longer. Native American and rural women are disadvantaged in geographic access based on travel times to breast imaging. This work informs potential interventions to reduce inequities in access and utilization.

\section{Keywords}

Travel time; access; mammography; breast imaging; disparities

\section{Introduction}

Breast imaging is a key component of screening, diagnosis, treatment, and surveillance for breast cancer. Evidence-based U.S. guidelines recommend biennial mammography for average-risk women ages 50-74 years, with a preference-based approach for women ages 40-49 years [1]. Every year in the U.S., approximately 37 million screening and diagnostic mammograms are performed [2]. This translates to an estimated 70\% of women aged 50-74 years undergoing screening mammography biennially, with between 9-14\% receiving further diagnostic breast imaging (mammography, ultrasound, MRI) and/or biopsy [3]. The full scope of use of breast ultrasound and breast MRI is not known, but these are important breast imaging modalities for specific clinical scenarios. Ultrasound is predominantly used in the diagnostic work-up of imaging or clinical findings, and potentially screening a subset of women at increased breast cancer risk. Although there are few data supporting its use for screening based solely on higher mammographic breast density use of additional imaging technologies might be more common as breast density reporting laws are implemented. Recently passed breast density reporting laws in several states mandate that women with dense breasts be directly informed of their increased cancer risk and may benefit from supplemental screening beyond mammography [4]. Breast MRI is currently the most sensitive test for breast cancer detection, and is recommended by groups including the American Cancer Society (ACS) and the National Comprehensive Cancer Network (NCCN) 
annually as an adjunct to mammography for screening of women at high risk for breast cancer [5,6]. Overall, mammography, ultrasound, and MRI or a combination of these examinations are critical in detecting, diagnosing and characterizing extent of breast cancer, and also in excluding malignancy of the breast. For each of the major clinical areas in which breast imaging is used, geographic access may determine both the availability and uptake of breast imaging services [7-11], which in turn may influence treatment decisions and ultimately outcomes $[12,13]$.

Prior studies have shown that longer travel time to care is associated with lower utilization of specialized services. For example, evidence suggests that travel time to breast imaging facilities may influence women's utilization of breast cancer treatment, with longer travel times associated with a greater likelihood of mastectomy instead of breast-conserving surgery $[8,10]$. However, there is a lack of evidence regarding travel times required for different breast imaging modalities, despite the fact that the modalities of mammography, ultrasound and breast MRI comprise the core of recommended screening and diagnostic imaging tests. While women's ability to utilize breast services is multifactorial, proximity of services and travel time burden is one important component that warrants consideration [15-17]. Vulnerable populations have poorer access to health care resources [18-21], which may be due in part to geographic access barriers.

Our manuscript examines travel time to three types of breast imaging services-mammography, ultrasound, and MRI- for ZIP code areas of the continental U.S. We describe population characteristics in relation to travel time for each of these breast imaging modalities, and provide an overall view of geographic access to breast imaging in the U.S. for subgroups of women.

\section{Methods}

\section{Study Population and Data}

We used 2010 Census data to determine the number of women aged 30 years and older in each census block group of the contiguous U.S. [22]. The age criterion was based on ACS guidelines, which recommend screening mammograms for high-risk women starting at age 30 , as well as recognizing that an estimated 12,000 women under age 40 are diagnosed with breast cancer each year [23, 24]. We excluded Alaska and Hawaii due to the lack of quality road based geospatial data. Population characteristics were based on the U.S. Census 2010 and included: age, race/ethnicity, education and median household income at the block group level. Rurality is based on the four-tier rural-urban commuting area (RUCA) designation [25, 26]. Briefly, these designations are made based on commuting patterns of the population for given areas, and include: 1. Urban Core; 2. Sub-Urban; 3. Large Rural Town; 4. Small Town/Isolated Rural [25,26].

\section{Location of Breast Imaging Modalities}

We took a utilization-based approach to identify breast imaging location, similar to prior studies [27-30]. Specifically, using a 20\% sample of Medicare Part B claims data (Carrier and Outpatient files) from $2004-2008$, we identified claims and the associated ZIP codes for 
mammography, breast ultrasound, and breast MRI using ICD-9 and Current Procedural Terminology (CPT) codes (Table 4). 5,846 unique ZIP codes were identified of which 5,497 provided mammography, 5,046 breast ultrasound, and 1,783 breast MRI. We used ArcGIS v10.1 to geocode each of these breast imaging modalities to the related ZIP code centroid.

\section{Travel Time Calculation}

We obtained the TIGER/Line shapefiles [31] and calculated the centroid of each block group. Using the Network Analyst extension in ArcGIS v.10.1 and the Streetmap North America (N.A.) network dataset [32], we calculated travel time from each block group centroid to the nearest facility offering: 1) mammography, 2) breast ultrasound, and 3) breast MRI. Continuous measures of travel time were generated for the contiguous U.S. for each modality. We categorized these times into (minutes): $<=30,31-60$, and $>60$ to generate a national map (Figure 1).

\section{Analyses}

We summarized the number of women aged 30 years and older for each travel time category and for each breast imaging modality. We then calculated the median and interquartile range of continuous travel time estimates for each modality, and the median travel times for population subgroups, including age, race/ethnicity, rurality, education, and median household income. Some research has shown that health care utilization is diminished if a service is more than 20 miles away [33], and several state health departments have advocated for no more than 30 minutes of travel for rural patients to see a physician [34]. All analyses were performed with Stata ${ }^{\circledR}$ v.11.2.

\section{Results}

Travel time categories (minutes) for each of the 215,798 block groups in the contiguous U.S. were mapped to visually compare travel times by geographic location and by modality (Figure 1). A total of 92,788,909 women aged 30 years and above were included in the population estimates for travel time. The majority of these women lived within 10 minutes of the nearest mammography and breast ultrasound services (67.2\% and 65.8\%), while just under half $(48.7 \%)$ lived that close to breast MRI (Table 1$)$. Approximately $85 \%$ of the $30+$ female population had 20 minutes or less travel time to nearest mammography or ultrasound. Breast MRI had the highest proportion of women living $>20$ minutes from the nearest location (29\%) (Table 1). There were no notable differences in the proportion of women in each travel time category by age (Table 5).

The overall median travel time to nearest mammography or ultrasound was 6 minutes (interquartile range [IQR], 4-13 minutes); for breast MRI it was 10 minutes (IQR, 5-26) (Table 2). Median travel times to the three breast imaging modalities differed markedly by population characteristics. Native American women had longer median travel times to all breast imaging modalities compared to the other racial/ethnic subgroups (Table 2). For breast MRI, Native Americans had median travel times that were twice as long as that of White women (median=24 $\mathrm{min}$; IQR, 8-72, and $12 \mathrm{~min}$; IQR 6-27, respectively), and three times longer than for other racial groups (Table 2). Median travel times for all breast 
imaging modalities were shorter for Black women compared to White women (Table 2). Travel time to MRI increased as rurality increased. For mammography and ultrasound, however, Sub-Urban areas had longer travel times than Large Rural Town areas (median for mammography: Sub-Urban, 19; IQR, 13-26, Large Rural Town, 8; IQR, 4-18). No notable differences in median travel times by education or median household income were seen (Table 2).

For mammography and ultrasound, only about $5 \%$ of the female population age $30+$ had greater than 30 minutes travel time. For breast MRI, the proportion was almost quadruple that $(19.8 \%$ ) (Table 3). The proportion of the Native American women age 30+ population with $>30$ minutes travel time to mammography and ultrasound was more than triple that for White women (39.6\% v. 12.6\%), and about 6 times higher than for Black women (6.4\%) and Pacific Islander women (7.2\%). Asian women had the lowest proportion $(\sim 2 \%)$ of women with travel time $>30$ minutes to mammography and ultrasound (Table 3 ). In relation to rurality, the proportion of women with travel time $>30$ minutes for breast MRI was high for all but Urban Core, but for mammography and ultrasound only Small Town/Isolated Rural Areas had a notably high proportion (Table 3). We examined the extent to which the effects of rurality and race/ethnicity were independently associated with travel time, and found that travel times for Native American women were longer regardless of rurality (Table 6). Differences in the proportion of women with a >30 minutes travel time to breast imaging modalities were modest in relation to educational attainment, but by income, women in the $4^{\text {th }}$ income quartile (lowest) had the lowest proportion in the $>30$ minutes travel time category for all imaging modalities (Table 3).

\section{Discussion}

This study is the first to provide data regarding U.S. geographic access to the three most common breast imaging modalities. We found that the vast majority of women age 30 and older live within 30 minutes of mammography, breast ultrasound, and breast MRI.

Geographic access was similar for mammography and ultrasound, but notably less for MRI. Marked differences in the proportion of women with a travel time of greater than 30 minutes to the nearest MRI were seen by race/ethnicity, rurality, and area-level median household income. A much higher proportion of Native American women had travel times of $>30$ minutes for all breast imaging modalities, compared to other racial/ethnic subgroups. A lower proportion of black compared to white women had $>30$ minutes of travel time to all three breast imaging modalities. A high proportion of rural women had $>30$ minutes travel time for all breast imaging, and most notably for MRI (86\%). Interestingly, the lowest income quartile had the lowest proportion with $>30$ minutes travel time, suggesting that geographic access is not a likely barrier to utilization in this group, although transportation and other factors may be.

We found that geographic access to breast MRI is the most limited among the breast imaging modalities studied. A phenomenon that is likely to be more pronounced with even new advance technologies such as digital breast tomosynthesis. There are multiple factors that could contribute to the more limited geographic availability of MRI, including the relatively higher expense of the equipment, and lower workforce capacity with expertise in 
this advanced technology. Diffusion of advanced technologies often occurs unevenly, and may in fact, never reach all geographic areas due to resource allocation strategies, such as certificates of need and creation of high-volume referral centers. MRI use has increased by 3.2\%-11.5\% annually from 2004-2008 based on national Medicare data samples [35,36]. This increase in advanced imaging use varies geographically by as much as 2-fold when examined at the level of the 10 national regions specified by the Centers for Medicaid and Medicare Services (CMS) [37].

Variation in geographic access by race/ethnicity and rurality has potential implications for fully understanding mechanisms underlying disparities in health care utilization and outcomes. For example, the approximately 2.5 million women aged $30+$ years who live $>30$ minutes from the nearest breast imaging of any kind, may be disadvantaged for early detection of breast cancer. This is supported by previous studies have shown that rural women have a significantly greater likelihood of more advanced stage when diagnosed with breast cancer than their more urban counterparts [38-40].

For Native American women, geographic access is relatively low for all breast imaging modalities for a large proportion of the population age 30+ years. In a 2008 Behavioral Risk Factor Surveillance System (BRFSS) report, mammography rates for Native American women were lower than for non-Hispanic white women, although the difference was not large (69\% v. 76\%, respectively) [41]. This could be due to Native American women finding ways to overcome barriers to travel time, or could reflect recall bias on the BRFSS survey instrument, or access to mobile vans, which we were not able to account for in this study.

Interestingly, for Black and urban women, geographic access seems less likely to be a barrier to screening compared to white and more rural women, respectively. In fact, comparable screening mammography rates have been shown for Black and White urban women [42]. However, studies examining utilization of services other than breast imaging have shown that, among urban cancer patients, Blacks were more likely than Whites to attend a NCI Cancer Center [43]. Race and rurality do seem to interact as rurality increases, with odds of attendance at an NCI Cancer Center [11] and use of screening mammography [42] dropping off significantly for increasingly rural Black individuals compared to increasingly rural Whites. The geographic component of disparities in health services utilization and patient outcomes is crucial to understand in order to identify the key causal factors underlying racial/ethnic disparities in health and health care.

Strengths of our study include calculation of travel time for all three major breast imaging modalities - mammography, ultrasound, and MRI, whereas prior studies at the national level have only included mammography, thus not capturing the full range of women's breast imaging needs and/or experiences. In addition, we characterized geographic access at the census block group level, rather than county as in prior national scale studies. However, we do note limitations in this work. First, we were only able to locate breast imaging facilities within ZIP codes, given the use of claims to identify those services so we were not able to include the actual address of the facility only the centroid of the census block. We do not measure time to mobile mammogram facilities, but do recognize that this limitation is unlikely to apply to our analysis of travel time to ultrasound or breast MRI. Also, as in most 
travel time studies, we used car-based travel estimates, thus did not account for other modes of transportation, such as subway, and did not explicitly incorporate public bus transportation into our estimates. Moreover, this analysis assumes that the study population has access to a vehicle. We also included only the contiguous U.S., thus are leaving out two states that have a relatively large proportion of native peoples and rural areas. Finally, the purpose of this study was to describe geographic access broadly, and did not seek to link access to utilization or outcomes. However, we recognize this as an important next step in more fully understanding utilization patterns for breast imaging, including sociodemographic disparities, potential underuse or overuse, and ultimately risk- or guideline-based care.

Geographic variability in access to breast imaging may be useful information for policy makers engaged in planning and resource allocation strategies. Understanding access may provide further insight regarding use/non-use patterns, particularly for subgroups of women and by imaging modality. For example, from this study we found a very large travel time for Native American women. Identification of regions, and the populations therein, that are subject to disadvantages in access can allow for targeted interventions, such as mobile breast imaging units, or increased availability of transportation services. Information on geographic access to breast imaging at the population level is an important first step in further understanding factors contributing to variation in breast cancer care and care outcomes. Characterizing utilization of breast imaging is an important facet of comparative effectiveness research for several reasons: 1) necessary to adjust for potential selection bias in use of imaging when comparing outcomes; 2) identification of subgroups of women for whom imaging is most effective; and 3) providing parameter inputs in decision analytic models. A first step in characterizing utilization is to determine potential access to imaging.

\section{Acknowledgments}

This work was supported by the National Institutes of Health -- National Cancer Institute Grant Number R01CA149365, RC2CA148259, and P01CA154292. CIL is supported in part by the National Institute of Health Grant Number L60 MD005349.

\section{References}

1. U.S. Preventive Services Task Force. Screening for breast cancer: U.S. Preventive Services Task Force recommendation statement. Ann Intern Med. 2009; 151:716-726. [PubMed: 19920272]

2. [Accessed October 10, 2013] U.S. Food and Drug Administration Mammography Quality Standards Act and Program National Statistics. 2013. Available at: http://www.fda.gov/RadiationEmittingProducts/MammographyQualityStandardsActandProgram/facilityScorecard/ ucm113858.htm

3. Hubbard RA, Kerlikowske K, Flowers CI, Yankaskas BC, Zhu W, Miglioretti DL. Cumulative probability of false-positive recall or biopsy recommendation after 10 years of screening mammography: a cohort study. Ann Intern Med. 2011; 155:481-92. [PubMed: 22007042]

4. Lee CI, Bassett LW, Lehman CD. Breast density legislation and opportunities for patient-centered outcomes research. Radiology. 2012; 264(3):632-6. [PubMed: 22919037]

5. [Accessed October 10, 2013] NCCN Guidelines for Patients| Breast Cancer. 2013. Available at: http://www.nccn.org/patients/guidelines/breast/files/assets/seo/page15.html

6. [Accessed October 10, 2013] American Cancer Society Guidelines for Breast Screening with MRI as an Adjunct to Mammography. 2007. Available at: http://www.cancer.org/healthy/ informationforhealthcareprofessionals/acsguidelines/breastcancerscreeningguidelines/index 
7. Boscoe FP, et al. Geographic proximity to treatment for early stage breast cancer and likelihood of mastectomy. The Breast. 2011; 20:324-328. [PubMed: 21440439]

8. Celaya MO, Rees JR, Gibson JJ, Riddle BL, Greenberg ER. Travel distance and season of diagnosis affect treatment choices for women with early-stage breast cancer in a predominantly rural population (United States). Cancer Causes Control. 2006:17, 851-856.

9. Elkin EB, et al. Geographic access and the use of screening mammography. Medical Care. 2010; 48:349-356. [PubMed: 20195174]

10. Onega $\mathrm{T}$, et al. The influence of travel time on breast cancer characteristics, receipt of primary therapy, and surveillance mammography. Breast Cancer Res Treat. 2011; 129(1):269-75. [PubMed: 21553117]

11. Onega T, Duell EJ, Shi X, Demidenko E, Goodman DC. Influence of place of residence in access to specialized cancer care for African Americans. Journal of Rural Health. 2010; 26(1):12-19. [PubMed: 20105263]

12. Lian M, Struthers J, Schootman M. Comparing GIS-based measures in access to mammography and their validity in predicting neighborhood risk of late-stage breast cancer. PLoS ONE. 2012; 7:e43000. [PubMed: 22952626]

13. American Cancer Society. [Last accessed 8/29/13] http://www.cancer.org/treatment/ understandingyourdiagnosis/examsandtestdescriptions/ mammogramsandotherbreastimagingprocedures/mammograms-and-other-breast-imagingprocedures-special-mammo-sit

14. National Comprehensive Cancer Network (NCCN). NCCN clinical practice guidelines in oncology. Breast Cancer V I. 2010:1-122.

15. Celaya MO, et al. Breast cancer stage at diagnosis and geographic access to mammography screening. Rural \& Remote Health. 2010; 10(2):1361-7. [PubMed: 20438282]

16. Henry KA, Boscoe FP, Johnson CJ, Goldberg DW, Sherman R, Cockburn M. Breast cancer stage at diagnosis: is travel time important? J Community Health. 2011:36, 933-942.

17. Onega T, Duell EJ, Goodman DC, Demidenko E, Shi X, Wang D. Geographic access to cancer care in the U.S. Cancer. 2008; 112(4):909-18. [PubMed: 18189295]

18. Haas JS, et al. Racial segregation and disparities in breast cancer care and mortality. Cancer. 2008:113, 2166-72. [PubMed: 18433484]

19. Centers for Disease Control and Prevention (CDC). CDC Health Disparities and Inequalities Report - United States, 2011. MMWR. 2011; 60(Supplement):1-114.

20. U.S. Department of Health and Human Services. National Center on Minority Health and Health Disparities. Social Determinants of Health Initiative. Available at: http://www.nimhd.nih.gov/ recovery/goSocialDeterm.asp

21. Peipins LA, Miller J, Richards TB, Bobo JK, Liu T, White MC, Joseph D, Tangka F, Ekwueme DU. Characteristics of US counties with no mammography capacity. J Community Health. 2012:37, 1239-1248.

22. United States Census. [Last accessed 7/4/2013] 2010. http://www.census.gov/2010census/data/

23. American Cancer Society. [Last accessed 8/31/13] http://www.cancer.org/treatment/ understandingyourdiagnosis/examsandtestdescriptions/ mammogramsandotherbreastimagingprocedures/mammograms-and-other-breast-imagingprocedures-special-mammo-sit

24. American Cancer Society. Breast Cancer Facts \& Figures 2011-2012. Atlanta: American Cancer Society, Inc;

25. Washington State Department of Health. [Accessed October 10, 2013] Guidelines for Using RuralUrban Classification Systems for Public Health Assessment. 2009. http://www.doh.wa.gov/ Portals/1/Documents/5500/RuralUrbGuide.pdf

26. Minnesota Population Center. National Historical Geographic Information System: Version 2.0. Minneapolis, MN: University of Minnesota; 2011.

27. The University of Washington, WWAMI Rural Health Research Center. [Last accessed 7/4/2013] http://depts.washington.edu/uwruca/ruca-data.php

28. Chan L, Hart LG, Goodman DC. Geographic access to health care for rural Medicare beneficiaries. J Rural Health. 2006; 22:140-146. [PubMed: 16606425] 
29. Hillner BE, et al. Intended versus inferred management after PET for cancer restaging. Medical Care. 2013; 51:361-367. [PubMed: 23481033]

30. Onega T, et al. Geographic and sociodemographic disparities in PET use by Medicare beneficiaries with cancer. J Am Coll Radiol. 2012; 9:635-642. [PubMed: 22954545]

31. 2010 TIGER/Line Shapefiles (machine-readable data files) prepared by the U.S. Census Bureau, 2012

32. Tele Atlas StreetMap Premium for ArcGIS v7.2. Lebanon, NH: Tele Atlas North America, Inc; 2005.

33. Brustrom JE, Hunter DC. Going the distance: how far will women travel to undergo free mammography? Mil Med. 2001; 166:347-349. [PubMed: 11315478]

34. Bosanac EM, Parkinson RC, Hall DS. Geographic access to hospital care: a 30-minute travel time standard. Medical Care. 1976; 14:616-624. [PubMed: 940405]

35. Dinan MA, et al. Changes in the use and costs of diagnostic imaging among Medicare beneficiaries with cancer, 1999-2008. JAMA. 2010; 303:1625-1631. [PubMed: 20424253]

36. Hillner BE, et al. Growth in the use of PET for six cancer types after coverage by Medicare: additive or replacement? JACR. 2012; 9:33-41. [PubMed: 22221634]

37. Parker L, Levin DC, Frangos A, Rao VM. Geographic variation in the utilization of noninvasive diagnostic imaging: national Medicare data, 1998-2007. AJR. 2010; 194:1034-1039. [PubMed: 20308507]

38. Gumpertz ML, Pickle LW, Miller BA, et al. Geographic patterns of advanced breast cancer in Los Angeles: associations with biological and sociodemographic factors (United States). Cancer Causes Control. 2006; 17(3):325-339. [PubMed: 16489540]

39. Parikh-Patel A, Bates JG, Campleman S. Colorectal cancer state at diagnosis by sociodemographic and urban/rural status in California, 1988-2000. Cancer. 2006; 107(5 Suppl):1189-95. [PubMed: 16835910]

40. Wang F, McLafferty S, Escamilla V, Luo L. Late-stage breast cancer diagnosis and health care access in Illinois. The Professional Geographer. 2008; 60:54-69. [PubMed: 18458760]

41. Steele CB, Cardinez CJ, Richardson LC, Tom-Orme L, Shaw KM. Surveillance for health behaviors of American Indians and Alaska Natives - findings from the Behavioral Risk Factor Surveillance System, 2000-2006. Cancer. 2008; 113(5 suppl):1131-41. [PubMed: 18720374]

42. Bennett KJ, Probst JC, Bellinger JD. Receipt of cancer screening services: surprising results for some rural minorities. J Rural Health. 2012; 28:63-72. [PubMed: 22236316]

43. Onega T, Duell EJ, Shi X, Demidenko E, Goodman D. Determinants of NCI Cancer Center attendance in Medicare patients with lung, breast, colorectal, or prostate cancer. J Gen Intern Med. 2008; 24:205-210. [PubMed: 19067086] 


\section{Take Home Points}

1. Travel time to mammography and ultrasound for most U.S. women (85\%) is $\leq$ 20 minutes and $70 \%$ for MRI.

2. Native American and rural women have a disproportionately high travel burden to breast imaging modalities.

3. Black and Asian women had the shortest median travel times to mammography, ultrasound, and MRI.

4. Characterizing travel time to major breast imaging modalities reveals marked differences among population subgroups and by modality. 

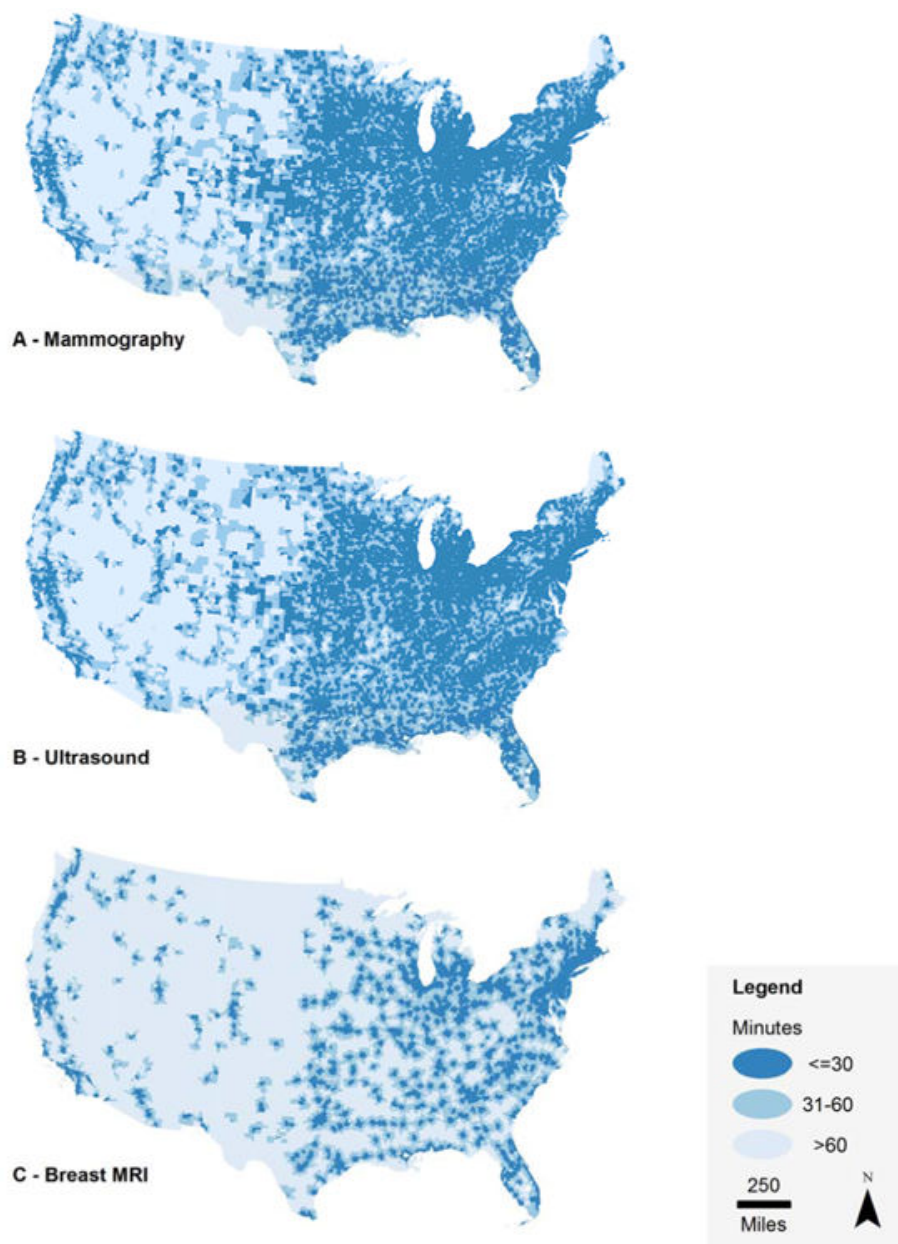

Figure 1. 


\section{Table 1}

Distribution of travel time to the nearest area with breast imaging services by modality for U.S. women aged 30 years and older $(\mathrm{N}=92,788,909)$.

\begin{tabular}{lcccc}
\hline & \multicolumn{4}{c}{ Travel Time to Nearest Breast Imaging Modality } \\
& \multicolumn{4}{c}{ \% U.S. Female Population (30 yrs. and older) } \\
\cline { 2 - 5 } & $<=\mathbf{1 0}$ minutes & $\mathbf{> 1 0} \boldsymbol{- 2 0}$ minutes & $\mathbf{> 2 0} \boldsymbol{-} \mathbf{3 0}$ minutes & $>\mathbf{3 0}$ minutes \\
\hline Mammography & 67.2 & 20.2 & 7.4 & 5.2 \\
Ultrasound & 65.8 & 20.6 & 7.8 & 5.7 \\
MRI & 48.7 & 22.2 & 9.2 & 19.8 \\
\hline
\end{tabular}




\section{Table 2}

Median travel times to breast imaging modalities in for the U.S. population of women aged 30 years and older, by socio-demographic categories.

\begin{tabular}{|c|c|c|c|c|}
\hline & \multirow[b]{2}{*}{ 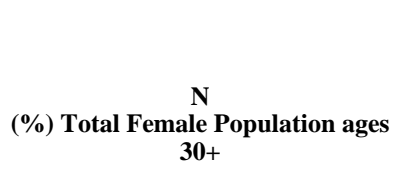 } & \multicolumn{3}{|c|}{ Median Travel Time in minutes; (Interquartile Range) } \\
\hline & & Mammography & Ultrasound & MRI \\
\hline Total Population & $92,788,909$ & $6(4-13)$ & $6(4-13)$ & $10(5-26)$ \\
\hline \multicolumn{5}{|l|}{ Race/Ethnicity 1} \\
\hline White & $68,867,272(74 \%)$ & $8(4-15)$ & $8(4-15)$ & $12(6-27)$ \\
\hline Black & $11,657,643(13 \%)$ & $6(3-9)$ & $6(3-9)$ & $8(5-16)$ \\
\hline Pacific & $109,922(0.12 \%)$ & $6(4-10)$ & $6(4-10)$ & $9(6-15)$ \\
\hline Asian & $4,186,628(4.5 \%)$ & $5(3-8)$ & $5(3-8)$ & $7(4-12)$ \\
\hline Native American & $731,039(0.79 \%)$ & $10(5-27)$ & $11(5-29)$ & $24(8-72)$ \\
\hline Other & $5,558,618(6.0 \%)$ & $5(3-8)$ & $5(3-8)$ & $7(5-13)$ \\
\hline Hispanic & $14,619,804(16 \%)$ & $5(3-9)$ & $5(3-9)$ & $8(5-14)$ \\
\hline \multicolumn{5}{|l|}{ Rurality $^{2}$} \\
\hline Urban Core & $64,012,576$ & $5(3-8)$ & $5(3-8)$ & $7(4-11)$ \\
\hline Suburban Areas & $10,859,046$ & $19(13-26)$ & $19(13-26)$ & $26(19-37)$ \\
\hline Large Town Areas & $8,966,731$ & $8(4-18)$ & $9(4-18)$ & $37(18-55)$ \\
\hline Small Town and Isolated Rural Areas & $8,921,069$ & $21(10-33)$ & $23(12-36)$ & $56(39-80)$ \\
\hline \multicolumn{5}{|l|}{ Education } \\
\hline Less than High School & $14,849,627$ & $6(3-12)$ & $6(3-13)$ & $10(5-27)$ \\
\hline High School & $29,860,888$ & $7(4-15)$ & $7(4-15)$ & $12(6-29)$ \\
\hline Some College & $30,198,034$ & $7(4-13)$ & $7(4-14)$ & $11(6-25)$ \\
\hline College & $18,025,960$ & $7(4-12)$ & $7(4-12)$ & $10(5-18)$ \\
\hline Graduate/Professional & $10,085,461$ & $6(3-13)$ & $6(4-11)$ & $9(5-17)$ \\
\hline \multicolumn{5}{|l|}{ Median Household Income ${ }^{3}$} \\
\hline 4th Quartile & $27,477,264$ & $7(4-11)$ & $7(4-12)$ & $9(5-16)$ \\
\hline 3rd Quartile & $24,795,180$ & $7(4-15)$ & $7(4-15)$ & $11(6-26)$ \\
\hline 2nd Quartile & $22,247,772$ & $7(4-16)$ & $7(4-17)$ & $13(6-39)$ \\
\hline 1st Quartile & $18,268,692$ & $5(3-10)$ & $5(3-10)$ & $9(5-36)$ \\
\hline
\end{tabular}

${ }^{1}$ Race and ethnicity are not mutually exclusive counts.

${ }^{2} 419$ ( $\left.0.2 \%\right)$ of census tracts were coded at the county level. 92 census tracts, representing 29,489 women age 30 and over were missing RUCA codes.

3 Median household income for quartiles: 4 th quartile: $\$ 35,572$ or less; 3rd quartile: $>\$ 35,5572-\$ 49,500 ; 2$ nd quartile: $>\$ 49,500-\$ 69,143 ; 1$ st quartile: $>\$ 69,143$ 


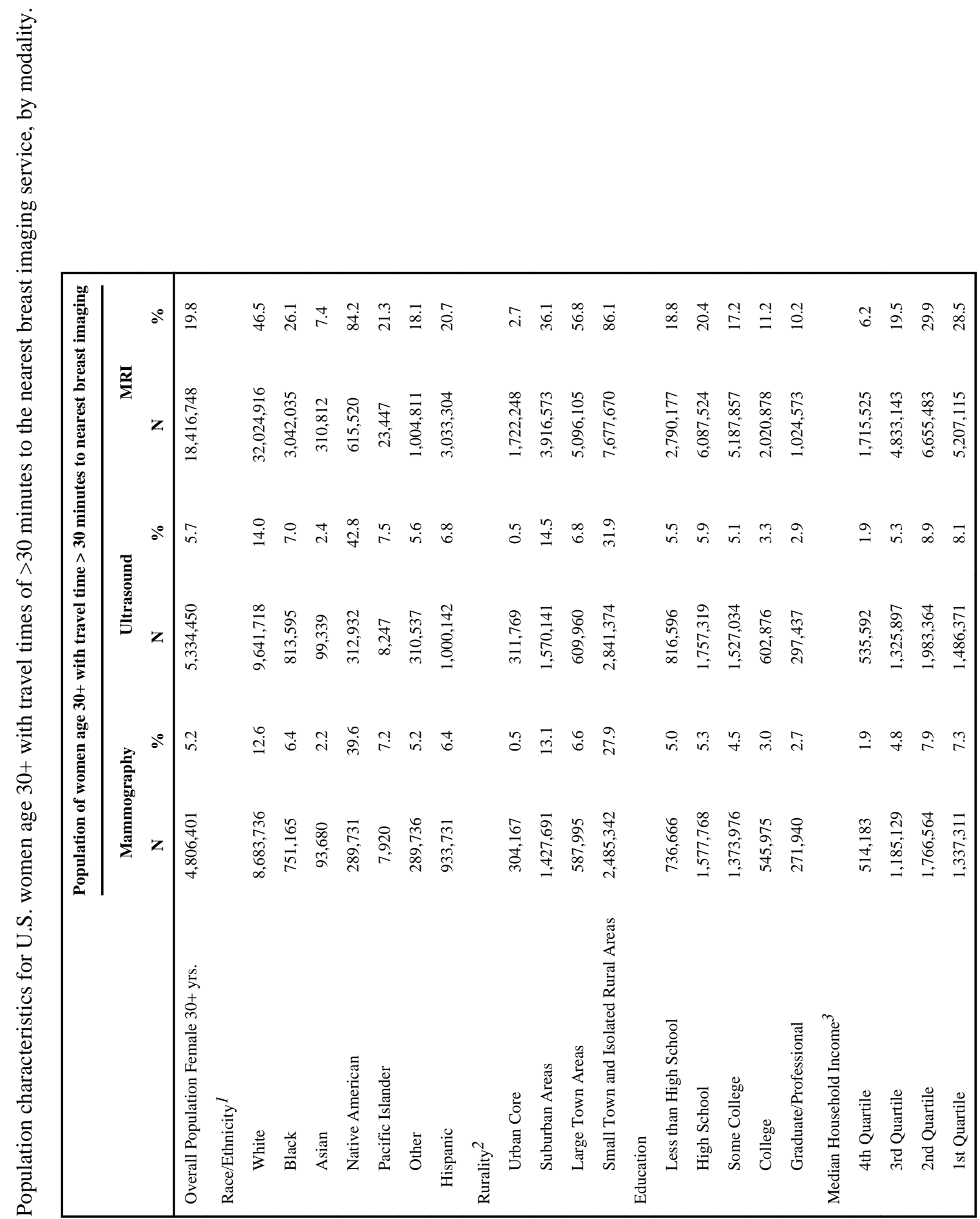




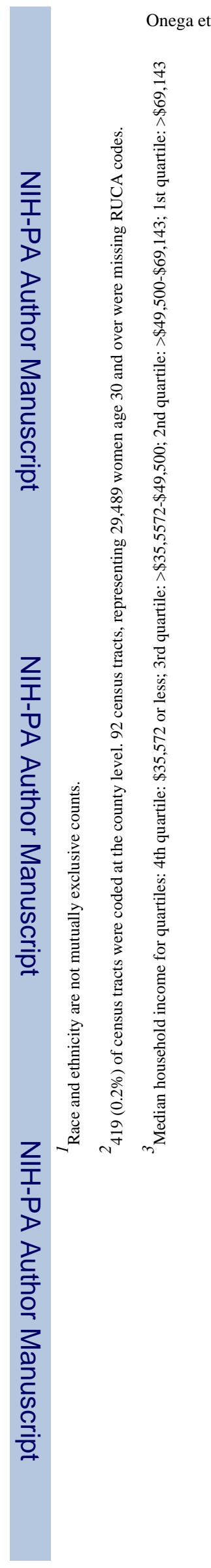

Page 15

$J$ Am Coll Radiol. Author manuscript; available in PMC 2015 September 01. 


\section{Table 4}

Codes used to ascertain breast imaging from Medicare claims.

\begin{tabular}{|c|c|c|}
\hline CODE & SOURCE & DESCRIPTION \\
\hline 76082 & CPT & COMPUTER Aided detection Diagnostic Mammogram \\
\hline 76090 & CPT & MAMMOGRAM, ONE BREAST X-RAY Breast E-C \\
\hline 76091 & $\mathrm{CPT}$ & MAMMOGRAM, BOTH BREASTS X-RAY Breast E-C \\
\hline G0204 & $\mathrm{HCPC}$ & X-RAY Breast DX MAMMO PRODUC DIR DIGTL \\
\hline G0205 & $\mathrm{HCPC}$ & X-RAY Breast DIAGNOSTIC MAMMOGRAPHY \\
\hline G0206 & $\mathrm{HCPC}$ & X-RAY Breast DX MAMMO PRODUC DIR DIGTL \\
\hline G0207 & $\mathrm{HCPC}$ & X-RAY Breast DIAGNOSTIC MAMMOGRAPHY \\
\hline 76083 & $\mathrm{CPT}$ & COMPUTER Aided detection Screening Mammogram \\
\hline 76085 & CPT & Digitization of Screening mammogram \\
\hline 76092 & $\mathrm{CPT}$ & MAMMOGRAM, SCREENING X-RAY Breast E-C \\
\hline 77057 & CPT & Screening mammography, bilateral \\
\hline G0202 & $\mathrm{HCPC}$ & X-RAY Breast SCR MAMMO PRODUC DIR DIGT \\
\hline G0203 & $\mathrm{HCPC}$ & X-RAY Breast SCREENING MAMMOGRAPHY \\
\hline \multicolumn{3}{|c|}{ Above plus } \\
\hline S8075 & $\mathrm{HCPC}$ & Computer analysis of full-field digital mammogram and further physician review for interpretation, mammography \\
\hline 77055 & CPT & Mammography, unilateral \\
\hline 77056 & CPT & Mammography, bilateral \\
\hline 87.37 & ICD9 & Other mammography \\
\hline 76645 & СРT & Breast ultrasound: \\
\hline 76093 & CPT & MRI Breast, Unil \\
\hline 76094 & $\mathrm{CPT}$ & MRI breast, Bil \\
\hline 77058 & CPT & MRI, ONE BREAST \\
\hline 77059 & CPT & MRI, BOTH BREASTS \\
\hline C8903 & $\mathrm{HCPC}$ & MRI W/CONT, BREAST, UNI \\
\hline C8904 & $\mathrm{HCPC}$ & MRI W/O CONT, BREAST, UNI \\
\hline C8905 & $\mathrm{HCPC}$ & MR NO CONTRST FLW W/CNTRS \\
\hline C8906 & $\mathrm{HCPC}$ & MRI W/CONT, BREAST, BI \\
\hline C8907 & $\mathrm{HCPC}$ & MRI W/O CONT, BREAST, BI \\
\hline C8908 & $\mathrm{HCPC}$ & MR NO CONTRST FLW CNTRST \\
\hline 88.73 & ICD9 & Diagnostic ultrasound of other sites of thorax (includes breast ultrasonography) \\
\hline 77021 & CPT & $\begin{array}{l}\text { Magnetic resonance guidance for needle placement (eg, for biopsy, needle aspiration, injection, or placement of } \\
\text { localization device) radiological supervision and interpretation }\end{array}$ \\
\hline
\end{tabular}




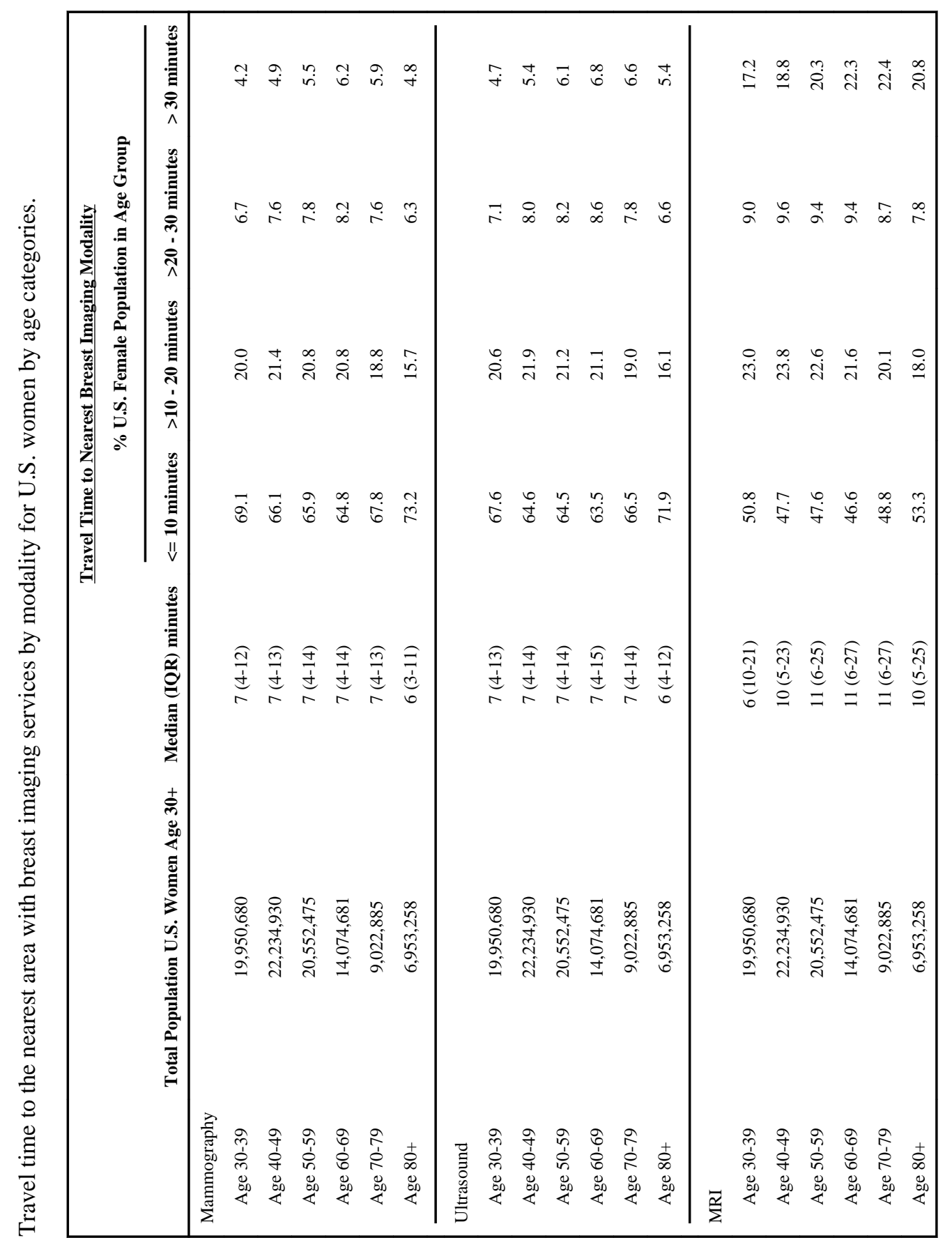

J Am Coll Radiol. Author manuscript; available in PMC 2015 September 01. 


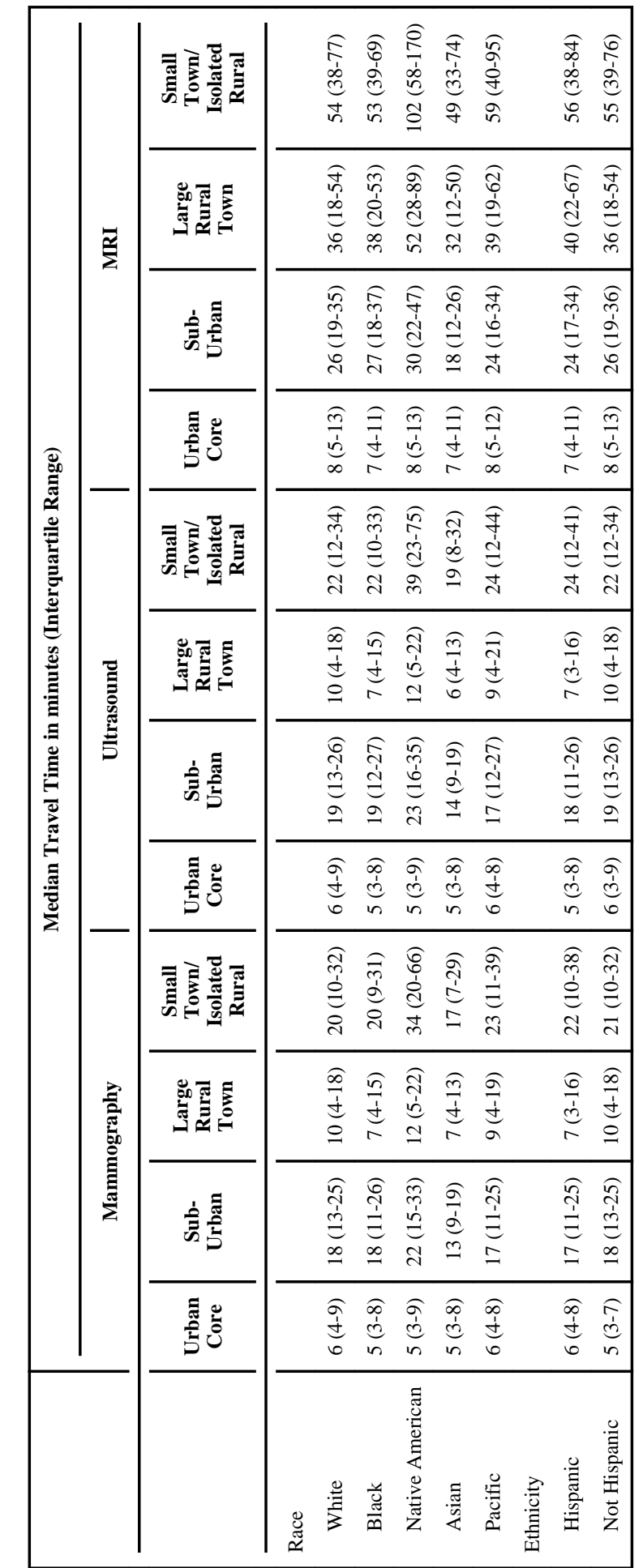

